\title{
Distribuição espacial dos fundos constitucionais de financiamento do Nordeste, Norte e Centro-Oeste ${ }^{1}$
}

\author{
Mansueto Facundo Almeida Júnior ${ }^{2}$ \\ Guilherme Mendes Resende ${ }^{3}$ \\ Alexandre Manoel Angelo da Silva ${ }^{4}$
}

\begin{abstract}
Resumo: O objetivo principal deste artigo é descrever os empréstimos dos fundos constitucionais de financiamento - Fundo Constitucional de Financiamento do Nordeste (FNE), Fundo Constitucional de Financiamento do Norte (FNO) e Fundo Constitucional de Financiamento do Centro-Oeste (FCO) - por município, investigando se a alocação dos recursos desses fundos concentra-se naqueles municípios que já são mais dinâmicos e se há concentração de empréstimos para grupos de municípios. Nessa investigação, entre outras análises, descrevem-se a disponibilidade de recursos nesses fundos e empréstimo por município. A principal conclusão deste estudo é que os empréstimos dos fundos constitucionais de financiamento não se direcionam de forma prioritária para os municípios mais pobres.
\end{abstract}

Palavras-chave: FNE, FNO, FCO, distribuição espacial.

\section{Spatial distribution of constitutional financing funds in Brazil: Northeast, North and Mid-West cases}

\footnotetext{
1 Este artigo é um resumo da primeira etapa da avaliação dos fundos constitucionais de financiamento no convênio MI/Anpec/Ipea. Gostaríamos de agradecer ao diretor da Dirur, Marcelo Piancastelli, ao diretor-adjunto, Aroudo Mota e ao coordenador, Alexandre Carvalho, pela estrutura técnica e pelos incentivos fornecidos no desenvolvimento da pesquisa. Os autores agradecem as sugestões dos pareceristas anômimos que em muito ajudaram para a melhoria do artigo.

2 Pesquisador do Instituto de Pesquisa Econômica Aplicada - Ipea. E-mail: mansueto@ipea.gov.br

3 Pesquisador do Instituto de Pesquisa Econômica Aplicada - Ipea. E-mail: guilherme.resende@ipea.gov.br

4 Pesquisador do Instituto de Pesquisa Econômica Aplicada - Ipea. E-mail: alexandre@ipea.gov.br
} 
Abstract: The main goal of this paper is to describe Northeast, North and MidWest Constitutional Financing Fund loans by municipalities, investigating if the resources allocations of the funds are concentrated in the most dynamics municipalities and if there are concentration loans for groups of municipalities. In this investigation, among other analyses, we describe the fund resource supply and loans by municipalities. The main conclusion of this paper shows that the Constitutional Financing Fund loans have not been directed to the poorest municipalities.

Key words: FNE; FNO; FCO; spatial distribution.

JEL: H70, H80

\section{Introdução}

Este artigo tem como objetivo descrever os empréstimos dos três fundos constitucionais de financiamento - Fundo Constitucional de Financiamento do Norte (FNO), Fundo Constitucional de Financiamento do Nordeste (FNE) e Fundo Constitucional de Financiamento do CentroOeste (FCO) - por município, investigando se a alocação dos recursos desses fundos concentra-se naqueles municípios que já são mais dinâmicos e se há concentração de empréstimos para grupos de municípios. As bases de dados utilizadas são os relatórios anuais do FNO, FNE e FCO divulgados pelo Ministério da Integração (MI), dados econômicos e sociais do Censo 1991 e 2000 e base de dados de empréstimo por município repassado ao Instituto de Pesquisa Econômica Aplicada (Ipea) pelos três bancos (Banco do Brasil - BB, Banco da Amazônia - Basa e Banco do Nordeste - BNB) responsáveis pela concessão de empréstimos com os recursos desses fundos constitucionais.

Antes de iniciar a análise de cada um desses três fundos, cabe uma breve explicação de como funcionam. Conforme se observa no Diagrama 1, as transações entre pessoas físicas e jurídicas formam a base para os dois tipos de impostos: Imposto de Renda (IR) e Imposto sobre Produtos Industrializados (IPI), cujo montante de $3 \%$ da arrecadação desses dois impostos representam as transferências do Tesouro Nacional para os três fundos constitucionais de financiamento. Desse total, o FNE fica com a parcela de $1,8 \%$ e os outros dois fundos (FCO e FNO) ficam cada um com uma parcela de $0,6 \%$.

Esses recursos são transferidos pelo Tesouro Nacional, por meio do MI, aos bancos que efetuam operações de empréstimos, com vistas à geração de emprego e renda, que contribui para parte do crescimento da arrecadação de IR e IPI e, assim, gera uma nova receita para esses fundos. Além da receita (de IR e IPI) e do retorno das operações de empréstimos (amortização $=$ principal + juros) descritos no Diagrama 
1, os juros Selic dos valores não emprestados são as outras fontes de receita dos fundos constitucionais de financiamento.

\section{DIAGRAMA $1-$ O CICLO DOS FUNDOS CONSTITUCIONAIS DE FINANCIAMENTO}

\section{Ciclo dos Fundos}

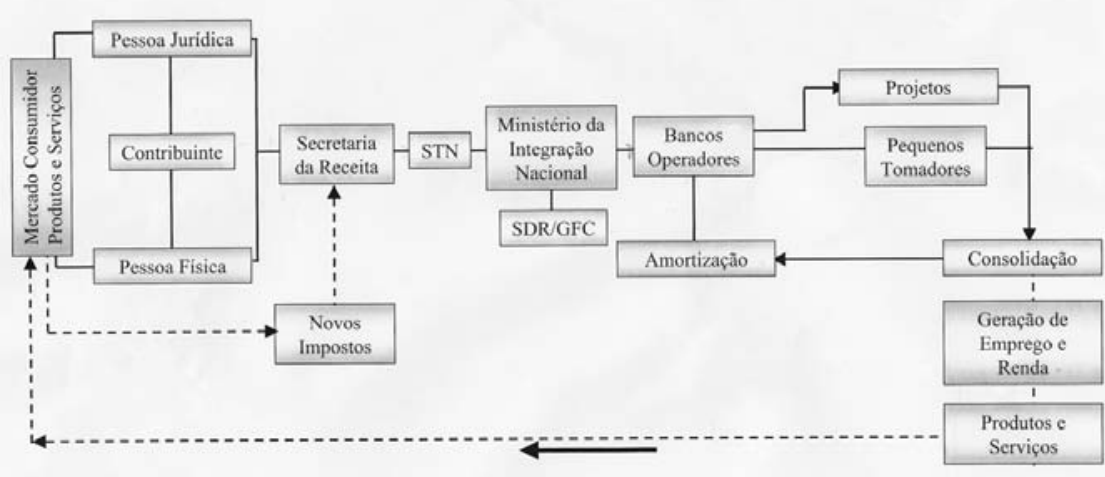

FONTE: Ministério da Integração Nacional.

É válido ainda mencionar que, mesmo ao considerar o retorno financeiro produzido pelo FNE, FNO e FCO aos cofres públicos da União, os recursos desses fundos representam uma parcela importante das despesas públicas. Em termos orçamentários, anualmente, esses recursos representam aproximadamente $0,42 \%$ da despesa primária (não-financeira) do governo federal, ou seja, cerca de $0,08 \%$ do PIB brasileiro ${ }^{5}$.

Além desta introdução, este artigo está dividido em mais cinco seções. A segunda seção descreve os empréstimos do Fundo Constitucional de Financiamento do Nordeste (FNE), enfatizando a distribuição de recursos por município, ao fazer uma série de cruzamentos com os dados censitários. O mesmo é feito nas duas seções seguintes para o Fundo Constitucional de Financiamento do Norte (FNO) e para o Fundo Constitucional de Financiamento do Centro-Oeste (FCO). Na quinta seção, faz-se uma análise exploratória dos dados espaciais, com vistas a anali-

5 Essas informações estão em conformidade com as "Despesas com Subvenções aos Fundos Regionais”, calculadas pela Secretaria do Tesouro Nacional, no Ministério da Fazenda. Essas despesas consideram o retorno das aplicações do FNE, FNO e FCO, a partir de um cálculo de subsídios implícitos. Esse cálculo foi acordado com o Fundo Monetário Internacional em 1999. 
sar se os recursos desses fundos constitucionais se direcionam para os municípios mais pobres. A sexta seção mostra as principais conclusões.

\section{Fundo Constitucional de Financiamento do Nordeste (FNE)}

Uma vez entendida a dinâmica de funcionamento dos fundos, analisa-se o FNE. Conforme se observa na Tabela 1, o FNE é o fundo com maior volume de recursos entre os três fundos constitucionais de financiamento. Em 2005, os três fundos constitucionais de financiamento receberam do Tesouro Nacional cerca de R $\$ 3,5$ bilhões, sendo que aproximadamente R $\$ 2,1$ bilhões foram transferidos para o FNE. As transferências do Tesouro para os fundos constitucionais determinam também o limite máximo de remuneração dos bancos operadores, já que esses não podem receber mais que $20 \%$ das transferências anuais do Tesouro Nacional a título de remuneração pela administração dos fundos ${ }^{6}$.

TABELA 1- RECURSOS ANUAIS REPASSADOS PELO TESOURO NACIONAL PARA OS FUNDOS CONSTITUCIONAIS - 1994-2005 (R\$ MIL)

\begin{tabular}{ccccc}
\hline Ano & FCO & FNO & FNE & Total \\
\hline 1994 & 372.300 & 372.300 & 1.116 .901 & 1.861 .501 \\
1995 & 382.472 & 382.472 & 1.147 .416 & 1.912 .360 \\
1996 & 359.379 & 359.379 & 1.078 .147 & 1.796 .905 \\
1997 & 370.889 & 370.889 & 1.112 .713 & 1.854 .491 \\
1998 & 377.092 & 377.092 & 1.131 .274 & 1.885 .458 \\
1999 & 388.549 & 388.549 & 1.165 .648 & 1.942 .746 \\
2000 & 433.367 & 433.367 & 1.300 .113 & 2.166 .847 \\
2001 & 523.624 & 523.624 & 1.570 .872 & 2.618 .120 \\
2002 & 602.074 & 602.074 & 1.806 .224 & 3.010 .372 \\
2003 & 626.346 & 677.506 & 1.826 .432 & 3.130 .284 \\
2004 & 695.440 & 695.440 & 2.086 .319 & 3.477 .199 \\
$2005 *$ & 705.300 & 705.300 & 2.115 .954 & 3.526 .554 \\
\hline
\end{tabular}

FONTE: Min. da Integração Nacional. OBS: valores atualizados para 2004 pela TR; *valores de 2005 correspondem à previsão de repasses para 2005 em 36 liberações a cada dez dias.

Cabe ressaltar que os valores da tabela acima não representam a disponibilidade real anual de empréstimo desses fundos. O volume disponível para emprestar em cada ano depende não só da parcela de transferência do IR e do IPI que cada fundo tem direito, mas também do retor-

6 O Basa e o BNB são remunerados com a taxa de administração de $3 \%$ sobre o patrimônio líquido do FNO e FNE respectivamente. Como o patrimônio desses fundos cresceu muito, essa taxa já ultrapassa o valor de 20\% dos repasses anuais do Tesouro Nacional. Alguns economistas defendem que essa taxa é excessivamente elevada e, assim, prejudica as operações de empréstimos, pois os bancos operadores seriam remunerados quer efetuem operações de empréstimos, quer não efetuem e (conseqüentemente) apliquem os recursos desses fundos em títulos públicos. 
no dos empréstimos feitos em anos anteriores, acrescido do volume de recursos disponíveis não emprestados nos exercícios anteriores e que são remunerados pela taxa Selic. Acrescida desses valores, a disponibilidade dos fundos para empréstimos em 2005 mais do que duplica, passando para $\mathrm{R} \$ 7,7$ bilhões. Essa diferença é particularmente elevada para o FNE, que contava em 2005 com uma disponibilidade de recursos para empréstimo da ordem de quase $\mathrm{R} \$ 5$ bilhões. No Gráfico 1, é possível observar que, em apenas dois anos, no período de 1996 a 2004, as aplicações do FNE superaram os repasses anuais feitos pelo Tesouro Nacional.

GRÁFICO 1- REPASSES ANUAIS DO TESOURO NACIONAL E APLICAÇÕES DO FNE (1994-2004)

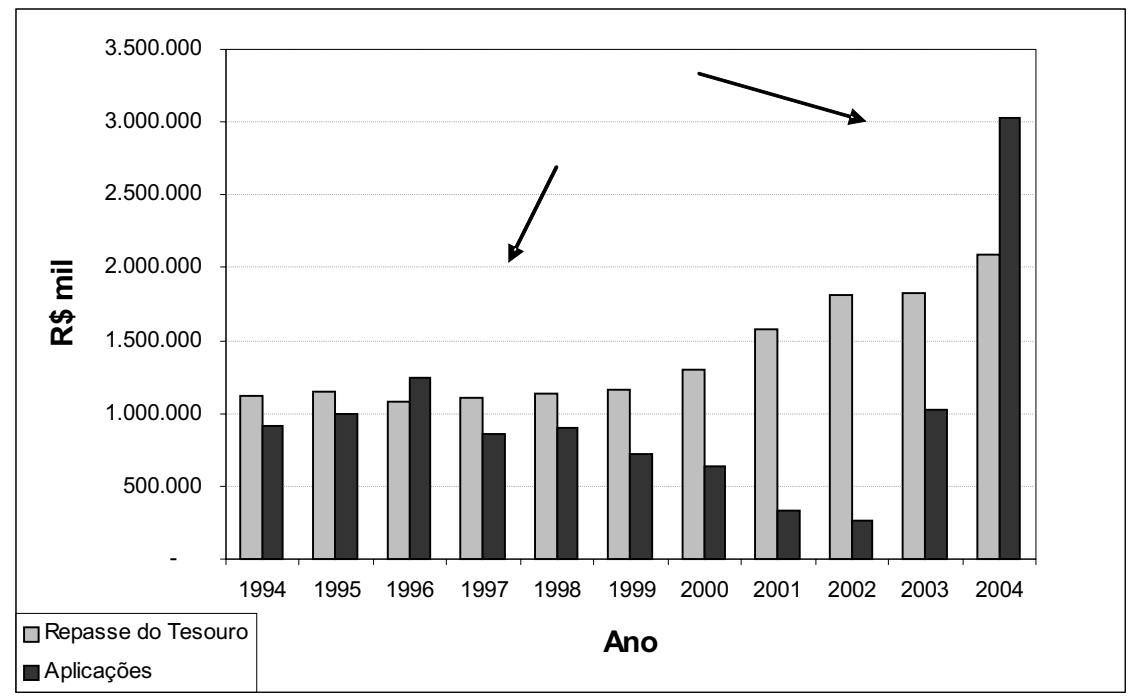

FONTE: Min. da Integração Nacional. OBS: valores atualizados para 2004 pela TR.

É interessante questionar o que ocorreu pós-1998 com o FNE, já que houve continuação na administração do BNB e essa administração havia adotado várias medidas para facilitar a liberação de empréstimos entre 1995 e 1998. Há duas explicações complementares para explicar a forte queda na concessão de empréstimos pelo Banco do Nordeste com recursos do FNE no segundo mandato (1998-2002) da administração anterior. Primeiro, o volume de empréstimos do banco em relação ao seu capital próprio cresceu muito, alcançando o limite estabelecido pelo Acordo de Basiléia, acordo esse que o BNB passou a ter que observar a partir de 1998. Assim, a redução dos empréstimos decorreria de um limite natural imposto pela nova legislação bancária modificada ao 
longo da segunda metade dos anos 1990 por ocasião do Programa de Reestruturação e Ordenamento do Sistema Financeiro Nacional (Proer).

Segundo, o crescimento rápido dos empréstimos do FNE no período 1995-1998 ocorreu, simultaneamente, ao crescimento elevado da inadimplência. Como a legislação em vigor na época estabelecia que $100 \%$ do risco do empréstimo eram de responsabilidade dos bancos operadores e não do fundo, o BNB ficou com um volume elevado de provisão para devedores duvidosos, reduzindo sua capacidade de conceder novos empréstimos, o que levou a uma intervenção do Banco Central. A questão até hoje não respondida é o que levou os empréstimos com recursos do FNE atingirem um nível de inadimplência tão elevado no período pós-1998. Uma possível explicação é a influência política no $\mathrm{BNB}$, indagação essa que carece de comprovação, pois não se explica, por exemplo, porque essa influência seria maior no caso do BNB do que no Basa ou mesmo no Banco do Brasil, que também são bancos públicos.

Em resumo, com os novos limites estabelecidos pelo acordo da Basiléia e o crescimento expressivo da provisão para devedores duvidosos, o BNB ficou sem possibilidade de transformar o aumento dos repasses do Tesouro Nacional em novas operações de crédito. Fez-se necessária uma capitalização no Banco do Nordeste pelo governo federal, que ocorreu em 2002, a qual permitiu ao BNB aumentar a concessão de empréstimos com recurso do FNE, a partir de 2003.

\subsection{Distribuição espacial dos recursos do FNE}

O FNE tem como área de atuação 1.952 municípios da região Nordeste, do norte de Minas Gerais e do norte do Espírito Santo. Na Tabela 2, pode-se observar que Bahia, Ceará e Pernambuco são os três Estados que mais receberam recursos do FNE de 1989 a 2004. No entanto, quando se observa o critério de saldo per capita, a Área Mineira de alcance do FNE e os Estados Piauí e Sergipe passam a ser os três de maior acesso aos recursos do FNE 
TABELA 2- SALDO FNE E SALDO FNE PER CAPITA DOS ESTADOS DA ÁREA DE ATUAÇÃO DO FNE

\begin{tabular}{lrrr}
\hline \multicolumn{1}{c}{ Estados } & $\begin{array}{c}\text { Saldo FNE - } \\
\text { RS de 2004 }\end{array}$ & $\begin{array}{c}\text { População em } \\
\mathbf{2 0 0 0}\end{array}$ & $\begin{array}{c}\text { Saldo FNE per } \\
\text { capita }\end{array}$ \\
\hline Alagoas & 903.112 .000 & 2.822 .621 & 320 \\
Bahia & 3.494 .267 .000 & 13.070 .250 & 267 \\
Ceará & 2.405 .165 .000 & 7.430 .661 & 324 \\
Maranhão & 1.050 .725 .000 & 5.651 .475 & 186 \\
Paraíba & 782.672 .000 & 3.443 .825 & 227 \\
Pernambuco & 2.278 .216 .000 & 7.918 .344 & 288 \\
Piaú & 1.115 .712 .000 & 2.843 .278 & 392 \\
Rio G. do Norte & 701.623 .000 & 2.776 .782 & 253 \\
Sergipe & 654.718 .000 & 1.784 .475 & 367 \\
Área Capixaba de & & & \\
alcance do FNE & & 736.427 & 128 \\
Área Mineira de & 94.456 .000 & & \\
Alcance do FNE & & & \\
\hline Totais & 968.624 .000 & 2.417 .239 & $\mathbf{2 8 4}$ \\
\hline
\end{tabular}

FONTE: Min. da Integração Nacional e IBGE. OBS.: os dados de população para Minas Gerais e Espírito Santo referem-se apenas à população daqueles municípios da área de atuação do FNE. * Municípios do Espírito Santo que estão na área de alcance do FNE. **Municípios de Minas Gerais que estão na área de alcance do FNE.

Um ponto importante no debate sobre as liberações de recursos dos fundos constitucionais de financiamento é saber se existe uma relação negativa entre saldo dos empréstimos per capita e PIB (ou renda) per capita. Se a liberação dos recursos do FNE responderem puramente à demanda das empresas, essa relação deve ser positiva já que os municípios mais ricos (PIB per capita maior) demandariam mais recursos do fundo. Se as liberações tivessem como objetivo principal reduzir as desigualdades intra-regionais, essa relação deveria ser negativa: quanto maior o PIB per capita do município, menor o saldo do empréstimo per capita para aquele município.

Nos Mapas 1 e 2, identificam-se, respectivamente, os municípios na área de atuação do FNE com menor IDH-M (inferior o,6) e os municípios com maior saldo do FNE per capita (superior a R\$300). Casos os empréstimos do FNE fossem prioritariamente dirigidos para aquelas áreas de menor IDH-M, esses dois mapas deveriam ser iguais, ou seja, a área marcada no Mapa 1 deveria ser idêntica àquela marcada no Mapa 2. Todavia, não é isso que ocorre?

O Mapa 1 representa um total de 761 municípios; o Mapa 2, 686 municípios. Apenas 262 municípios aparecem simultaneamente nos dois

7 Dado que não existe uma relação clara entre IDH-M e saldo dos empréstimos do FNE per capita, é possível tentar identificar se existe alguma relação entre PIB per capita dos municípios e o saldo dos empréstimos per capita do FNE. Isso foi feito e novamente não se encontra qualquer relação clara entre essas duas variáveis, o que indica que as liberações do FNE não se direcionam prioritariamente para os municípios mais pobres. 
mapas: IDH-M inferior a o,6 e saldo do FNE per capita maior que R\$ 300. Em outras palavras, dos 761 municípios na área de atuação do FNE com IDH-M inferior a o,6, apenas 262 desses municípios (34\%) estão entre aqueles que receberam mais de $\mathrm{R} \$ 300$ per capita de empréstimo do FNE até dezembro de 2004. Isso indica que, historicamente, os empréstimos do FNE não foram alocados para aqueles municípios de menor IDH-M, o que sugere que as liberações de recursos do FNE devem responder à demanda por financiamento naqueles municípios onde já existe algum dinamismo econômico. No Mapa 2, isso é particularmente fácil de ser observado na parte oeste da região Nordeste, onde predominam as plantações de soja.

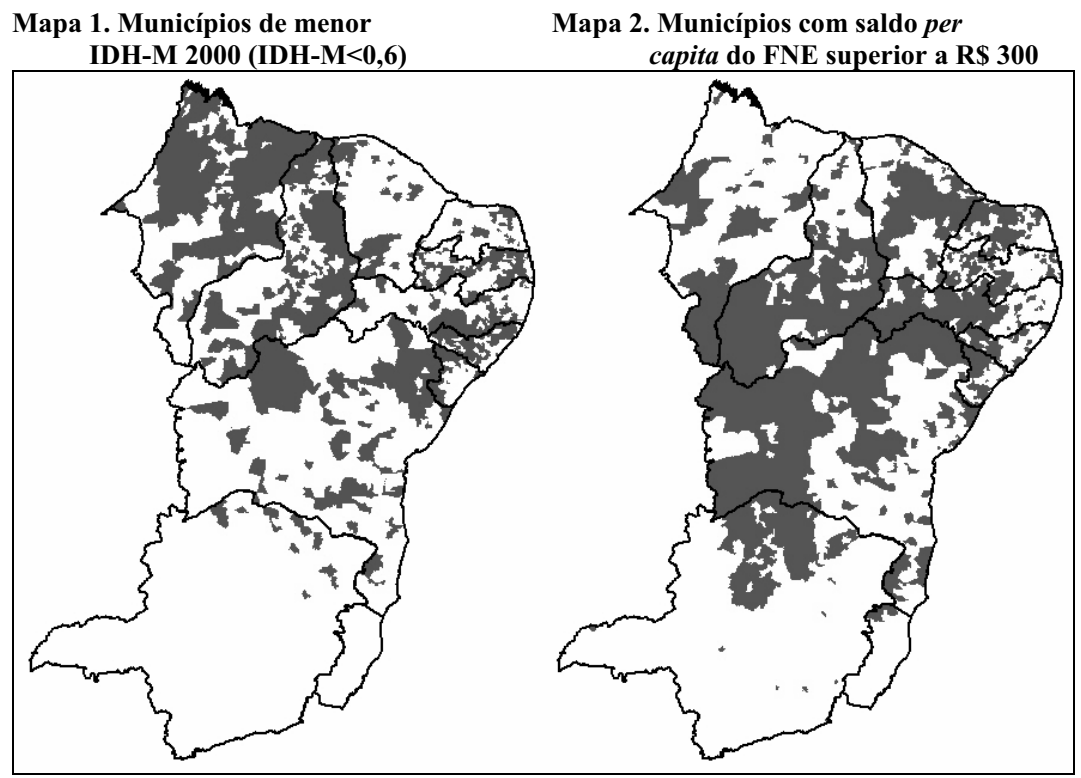

Fonte: Min. da Integração Nacional e Atlas do Desenvolvimento Humano.

Dado que maior parcela dos recursos dos fundos é alocada para municípios que não são aqueles de menor IDH-M, é possível que exista o paradoxo de que os recursos do FNE estejam contribuindo para o aumento do dinamismo econômico da região Nordeste, norte de Minas Gerais e Espírito Santo, ao mesmo tempo em que contribui para o crescimento das desigualdades intra-regionais. Essa é justamente a crítica que se fazia à forma tradicional de caracterizar o problema regional como um problema macrorregional, pois no Nordeste existem sub-regiões com 
algum dinamismo econômico e com capacidade de atrair investimentos produtivos, enquanto outros espaços geográficos dessa região carecem de um dinamismo econômico capaz de atrair investimentos privados. Apenas no governo Lula, em seu primeiro mandato, na gestão do Ministério da Integração, passou-se a caracterizar o problema regional na esfera sub-regional, de modo a sugerir a alocação dos recursos dos fundos constitucionais de financiamento para áreas mais pobres dentro de cada região.

\subsubsection{Saldo de empréstimos do FNE: municípios que mais receberam recursos}

Na Tabela 3, mostra-se por faixa de IDH-M o número de municípios na área de atuação do FNE e o número de municípios cujo saldo per capita em dezembro de 2004 era superior a $\mathrm{R} \$ 1.500,00$. Em 2004, apenas 3\% dos municípios da área de atuação do FNE tinham saldo per capita superior a esse valor e desses municípios o maior número absoluto estava naquelas áreas de maior IDH-M (acima de 0,591). Adicionalmente, o grupo de municípios de maior IDH-M $(0,649-0,862)$ tem uma representação percentual maior no grupo dos que mais recebem recursos do FNE. Isso sugere, conforme acima alertado, que os empréstimos do FNE respondem mais à demanda daquelas áreas mais desenvolvidas do que ao objetivo de redução das desigualdades intra-regionais.

TABELA 3- NÚMERO DE MUNICÍPIOS COM SALDO PER CAPITA DE EMPRÉSTIMO DO FNE ACIMA DE R\$ 1.500,00 POR FAIXA DE IDH

\begin{tabular}{ccccc}
\hline IDH & $\begin{array}{c}\text { Municípios com Saldo } \\
\text { FNE Per Capita }>\text { R } \\
1.500(\mathrm{a})\end{array}$ & $\begin{array}{c}\text { Municípios na área de } \\
\text { atuação do FNE (b) }\end{array}$ & (a) / (b) - \% \\
\hline $\mathbf{0 , 4 6 9 - 0 , 5 9 1}$ & 11 & 614 & $2 \%$ \\
$\mathbf{0 , 5 9 1 - 0 , 6 4 9}$ & 31 & 887 & $3 \%$ \\
$\mathbf{0 , 6 4 9 - 0 , 8 6 2}$ & 16 & 447 & $4 \%$ \\
\hline Totais & $\mathbf{5 8}$ & $\mathbf{1 . 9 4 8}$ & $\mathbf{3 \%}$ \\
\hline
\end{tabular}

FONTE: Min. da Integração Nacional e Ipeadata

Quando se cruzam os dados de empréstimo do FNE para o grupo de 58 municípios com saldo do FNE per capita acima de R $\$ 1.500$ com dados de renda per capita ou IDH-M não é possível encontrar qualquer relação. Uma característica que se destaca na identificação da principal atividade econômica dos municípios com maior saldo per capita do FNE é a presença daqueles municípios plantadores de soja no Nordeste. Esse é o caso, por exemplo, para os municípios de Correntina, Jaborandi, Riachão das Neves 
e Formosa do Rio Preto, na Bahia e Tasso Fragoso, no Maranhão. Os Estados do Piauí e Bahia são os Estados com maior número de municípios com saldo per capita do FNE superior a R $\$ 1.500,18$ e 19 municípios, respectivamente. Como o Piauí tem 222 municípios e a Bahia quase o dobro (417), o Piauí se destaca como o Estado com maior participação percentual de municípios (8\%) entre aqueles que mais receberam recursos do FNE pelo critério per capita.

É importante não confundir os municípios que mais receberam recursos per capita com aqueles de maior saldo do FNE. Os municípios que mais receberam recursos per capita (acima de $\mathrm{R} \$ 1.500$ ) são, geralmente, municípios de população pequena, enquanto os municípios com maior saldo do FNE (acima de R $\$ 50$ milhões) são, na sua maioria, municípios populosos, incluindo todas as capitais dos Estados do Nordeste. O grupo de 58 municípios com saldo per capita do FNE superior a R $\$$ 1.500 tem uma população de 1 milhão de habitantes. Por sua vez, aqueles municípios que receberam um volume de recursos do FNE superior a R $\$ 50$ milhões representam 41 municípios com uma população de 13,7 milhões de habitantes.

Nos Mapas 3 e 4, mostram-se, respectivamente, os municípios com saldo do FNE per capita superior a $\mathrm{R} \$ 1.500$ (58 municípios) e aqueles com saldo do FNE total acima de $\mathrm{R} \$ 50$ milhões. Apenas 12 dos 58 municípios com saldo per capita superior a $\mathrm{R} \$ 1.500$ estão também entre aqueles que receberam mais de $\mathrm{R} \$ 50$ milhões de empréstimos do FNE. Entre esses municípios, destacam-se aqueles localizados na região metropolitana de capitais (Simões Filho (BA) e São Cristóvão (SE)) e aqueles municípios que têm sido foco de políticas públicas de desenvolvimento (Petrolina (PE) e Horizonte (CE)). 
Mapa 3. Municípios com saldo per capita do FNE superior a $\mathbf{R} \$ \mathbf{1 . 5 0 0 , 0 0}$
Mapa 4. Municípios com saldo do FNE superior a R\$ 50 milhões

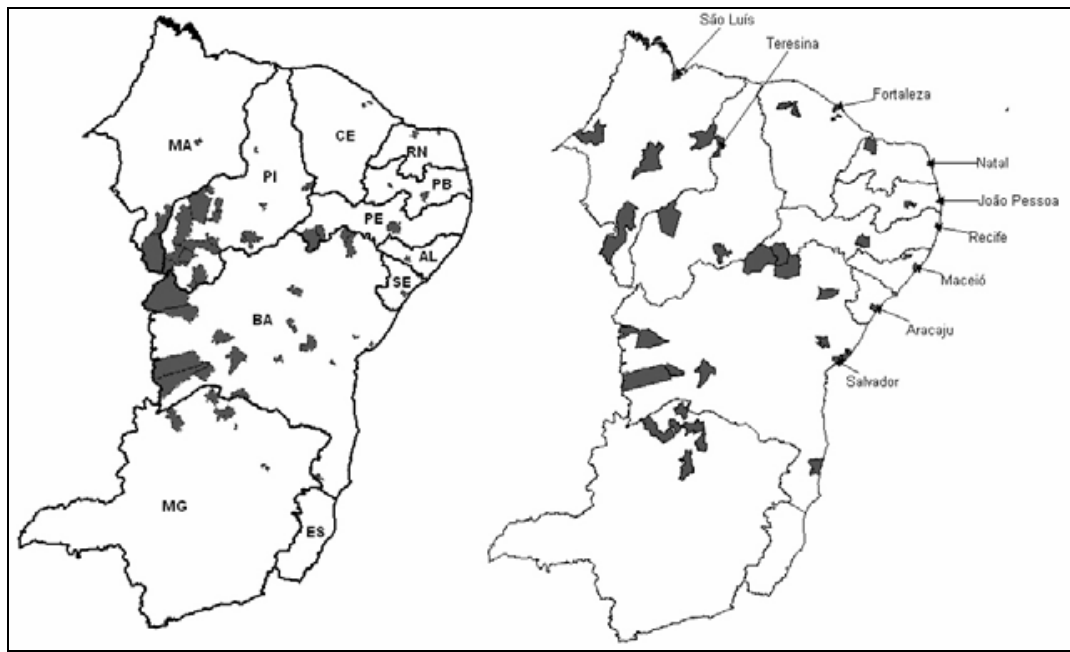

FONTE: Elaboração própria.

\section{Fundo Constitucional de Financiamento do Norte \\ (FNO)}

O Fundo Constitucional de Financiamento do Norte (FNO) tem por objetivo contribuir para o desenvolvimento econômico e social da Região Norte, mediante a execução de programas de financiamento às atividades produtivas dos setores agropecuário, industrial, agroindustrial, mineral, infra-estrutura, de turismo, comércio e serviços. Esse fundo é operacionalizado pelo Banco da Amazônia (Basa), que possui como área de atuação os Estados da Região Norte (Acre, Amazonas, Amapá, Pará, Roraima, Rondônia e Tocantins) com seus 449 municípios.

Em relação aos repasses anuais do Tesouro e às aplicações, o FNO tem um histórico de aplicação melhor que o FNE. No período 1994-2004, em seis anos, o FNO aplicou valores superiores aos repasses anuais do Tesouro Nacional (Gráfico 2). Entretanto, da mesma forma que o FNE, em 2004, os recursos do FNO (repasses anuais + disponibilidade de recursos de anos anteriores + retorno das aplicações) eram superiores às suas aplicações. Nesse ano, o FNO tinha uma disponibilidade de recursos da ordem de $\mathrm{R} \$$ 1,7 bilhão de reais, tendo aplicado $\mathrm{R} \$ 1,3$ bilhão, equivalente a $77 \%$ dos recursos efetivamente disponíveis para serem emprestados. 
GRÁFICO 2- REPASSES ANUAIS DO TESOURO NACIONAL E APLICAÇÕES DO FNO (1994 -2004)

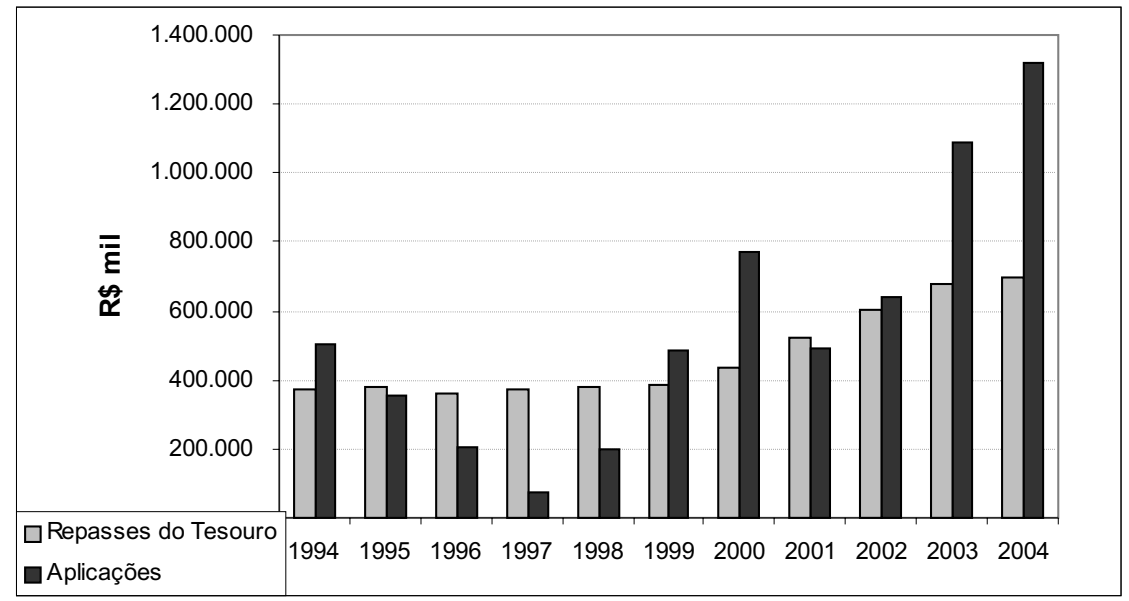

FONTE: Min. da Integração Nacional. OBS: valores atualizados para 2004 pela TR.

Da mesma forma ao que foi feito na seção anterior para o FNE, analisa-se o saldo dos empréstimos do FNO utilizando vários critérios e cruzando os dados de empréstimos com dados censitários. O objetivo desses cruzamentos é investigar se os recursos do FNO se direcionam, prioritariamente, para aqueles municípios menos desenvolvidos.

\subsection{Distribuição Espacial dos Recursos do FNO}

A Tabela 4 mostra alguns indicadores básicos do FNO para os Estados da Região Norte. Inicialmente, é possível observar que, até dezembro de 2004, metade dos recursos liberados pelo FNO foi para o Estado do Pará. Esse dado mostra que os empréstimos do FNO para os Estados são mais concentrados do que os empréstimos do FNE, mas essa concentração era de certa forma esperada, já que o Pará concentra $48 \%$ da população residente da Região Norte. Quando se corrigem os empréstimos pelo critério per capita, o Estado que se destaca na obtenção de recursos do FNO é Tocantins.

O Estado do Tocantins possui um saldo per capita dos empréstimos efetuados pelo FNO que é quase o dobro do valor observado para Roraima, que é o Estado com segundo maior saldo per capita do FNO. A explicação para isso está ligada à explicação para o elevado saldo do FNE na parte oeste da Região Nordeste: a presença das plantações de soja. 
TABELA 4- SALDO FNO E SALDO FNO PER CAPITA DOS ESTADOS DA REGIÃO NORTE

\begin{tabular}{lrrr}
\hline Estado & \multicolumn{1}{c}{$\begin{array}{c}\text { População } \\
\text { 2000 }\end{array}$} & $\begin{array}{c}\text { Saldo FNO - } \\
\text { R\$ de 2004 }\end{array}$ & $\begin{array}{c}\text { Saldo FNO Per Capita } \\
\text { (2004) }\end{array}$ \\
\hline Acre & 557.526 & 198.108 .000 & 355,33 \\
Amazonas & 2.812 .557 & 505.894 .000 & 179,87 \\
Amapá & 477.032 & 144.847 .000 & 303,64 \\
Pará & 6.192 .307 & 2.935 .616 .000 & 474,07 \\
Rondônia & 1.379 .787 & 691.475 .000 & 501,15 \\
Roraima & 324.397 & 211.489 .000 & 651,94 \\
Tocantins & 1.157 .098 & 1.429 .333 .000 & $1.235,27$ \\
\hline Total & $\mathbf{1 2 . 9 0 0 . 7 0 4}$ & $\mathbf{6 . 1 1 6 . 7 6 2 . 0 0 0}$ & $\mathbf{4 7 4 , 1 4}$ \\
\hline
\end{tabular}

FONTE: Min da Integração Nacional, Censo 2000 e IBGE.

Similarmente à seção anterior, tenta-se descobrir alguma relação entre os saldos dos empréstimos e variáveis econômicas nos municípios. A idéia é idêntica, ou seja, investigar se os municípios mais pobres da Região Norte conseguem mais créditos do FNO do que os municípios mais ricos.

Os dois mapas abaixo identificam os municípios na área de atuação do FNO com menor IDH-M (inferior 0,663) e os municípios com maior saldo do FNO per capita (superior a R $\$ 486)^{8}$, totalizando 199 municípios de um total de 449 municípios na Região Norte. Caso os empréstimos do FNO fossem prioritariamente dirigidos para aquelas áreas de menor IDH-M, esses dois mapas deveriam ser iguais, i.e, a área marcada do Mapa 5 deveria ser idêntica àquela marcada do Mapa 6. Contudo, não é isso que ocorre 9 .

Nos mapas a seguir, principalmente para os Estados do Amazonas e Pará, é possível observar que as áreas com maior saldo de empréstimo do FNO não coincidem com aquelas áreas de menor IDH-M. De fato, dos 199 municípios na área de atuação do FNO com IDH-M inferior a o,633, apenas 65 desses municípios (33\%) estão também entre aqueles que receberam mais de $\mathrm{R} \$ 486,00$ per capita de empréstimo do FNO até dezembro de 2004. Ou seja, historicamente, a maior parte dos empréstimos do FNO não foi alocada para aqueles municípios de menor IDH-M, o que sugere que as liberações de recursos devem responder à demanda por financiamento naqueles municípios onde já existe dinamismo eco-

8 O critério para estabelecer o valor de corte foi a média do IDH-M para o grupo de municípios da Região Norte: o,633. Como existem 199 municípios abaixo desta média, calcula-se o valor do saldo per capita do FNO no qual se tem um grupo equivalente de 199 municípios acima desse valor.

9 Dado que não existe uma relação clara entre IDH-M e saldo dos empréstimos do FNO per capita, é possível tentar identificar se existe alguma relação entre PIB per capita dos municípios e o saldo dos empréstimos per capita do FNO. Isso foi feito e novamente não se encontra qualquer relação clara entre essas duas variáveis, o que indica que as liberações do FNO não se direcionam prioritariamente para os municípios mais pobres. 
nômico. Isso é particularmente fácil de ser observado nos mapas para os Estados do Pará, Amazonas e Roraima.

\section{Mapa 5. Municípios com IDH-M (2000) inferior a 0,663 - 199 municípios}

Mapa 6. Municípios com saldo do FNO superior a R\$ 486,00 (2004) - 199 municípios

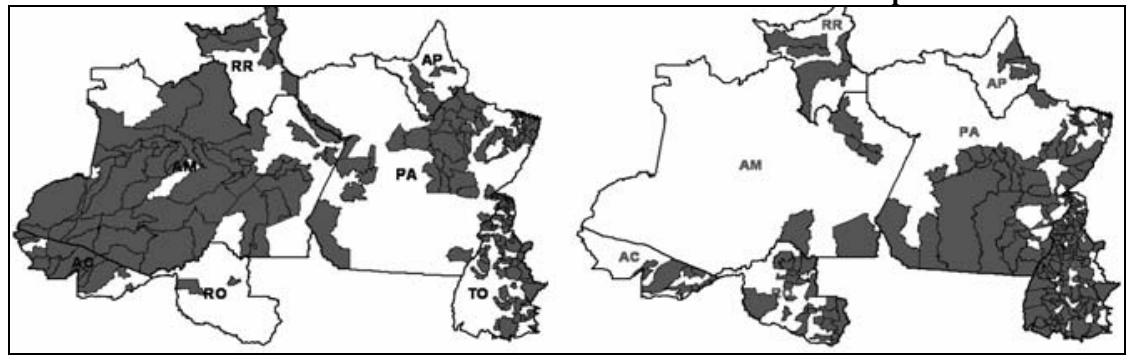

FONTE: Min. da Integração Nacional e Atlas do Desenvolvimento Humano.

Dado que a maior parcela dos recursos dos fundos é alocada para municípios de maior IDH-M, tem-se para o FNO o mesmo paradoxo identificado para o caso do FNE: os recursos do fundo contribuem para aumentar o dinamismo econômico da região ao mesmo tempo em que podem estar ocasionando o crescimento das desigualdades intra-regionais.

\subsubsection{Saldo de empréstimos do FNO: municípios que mais receberam recursos}

A Tabela 5 mostra por faixa de IDH-M o número de municípios na área de atuação do FNO e o número de municípios cujo saldo per capita em dezembro de 2004 era superior a $\mathrm{R} \$ 1.500,00$. Aproximadamente 15\% dos municípios da área de atuação do FNO tinham saldo per capita superior a esse valor no final de 2004 e desses municípios o maior número absoluto está naquelas áreas de IDH-M médio (acima de o,663 e menor que o,693). Comparando com o FNE, um maior número absoluto e relativo de municípios na Região Norte tem saldo per capita superior a $\mathrm{R} \$$ 1.500 e, nesse grupo, os municípios que predominam são aqueles de IDH-M médio e alto. Isso sugere, conforme já alertado, que os empréstimos desses fundos constitucionais parecem responder mais à demanda do que ao objetivo de redução das desigualdades intra-regionais. 
TABELA 5- NÚMERO DE MUNICÍPIOS COM SALDO PER CAPITA DE EMPRÉSTIMO DO FNO ACIMA DE R\$ 1.500,00 POR FAIXA DE IDH

\begin{tabular}{crrr}
\hline \multirow{2}{*}{ IDH } & \multicolumn{2}{c}{ Municípios com Saldo FN0 Municípios na área de } \\
& Per Capita $>$ R $\$ 1.500$ (a) & atuação do FNO (b) & (b) - \% \\
\hline $\mathbf{0 , 4 7 5 - 0 , 6 3 3}$ & 10 & 117 & $9 \%$ \\
$\mathbf{0 , 6 3 3 - 0 , 6 9 3}$ & 36 & 195 & $18 \%$ \\
$\mathbf{0 , 6 9 3 - 0 , 8 0 6}$ & 21 & 137 & $15 \%$ \\
\hline Totais & $\mathbf{6 7}$ & $\mathbf{4 4 9}$ & $15 \%$ \\
\hline
\end{tabular}

FONTE: Min. da Integração e Ipeadata.

Quando se cruzam os dados de empréstimo do FNO per capita com dados de renda per capita ou IDH-M para o grupo de 67 municípios com saldo per capita acima de $\mathrm{R} \$ 1.500$, não é possível encontrar qualquer relação. Em relação à comparação do saldo total com o saldo per capita é importante não confundir os municípios que mais receberam recursos per capita com aqueles que mais receberam recursos absolutos do FNO. Os municípios que mais receberam recursos per capita são, geralmente, municípios de população pequena. Apenas quatro do total de 67 municípios desse grupo têm uma população superior a 20 mil habitantes, sendo o maior município o de Paragominas no Pará. No total, a população dos municípios com saldo per capita dos empréstimos do FNO superior a $R \$ 1.500$ é de apenas 598 mil habitantes, enquanto a população dos demais municípios na área de atuação do FNO é de 12 milhões de habitantes.

Em relação aos municípios que tinham saldo total superior a $\mathrm{R} \$ 50$ milhões em 2004, esses são na sua maioria municípios populosos, totalizando 5,6 milhões de habitantes em um grupo de apenas 26 municípios, incluindo seis das sete capitais dos Estados da Região Norte. Esses 26 municípios responderam por $\mathrm{R} \$ 2,6$ bilhões (42\%) do total de $\mathrm{R} \$$ 6 bilhões emprestados até dezembro de 2004 pelo FNO e são municípios com IDH-M elevado (acima de o,69).

Um ponto importante a ser destacado é que semelhante ao FNE, no qual $20 \%$ dos municípios com saldo per capita superior a $\mathrm{R} \$ 1.500$ estão também entre aqueles com saldo maior do que $\mathrm{R} \$ 50$ milhões, no caso do FNO, cinco municípios de um total de 26 - Paragominas (PA), Miracema do Tocantins (TO), Altamira (PA), São Felix do Xingu (PA), e Bonfim (RR) - estão entre aqueles com maior saldo per capita e também com maior saldo total (acima de $\mathrm{R} \$ 50$ milhões).

Em resumo, no FNO, não é possível estabelecer uma relação clara entre os saldos dos empréstimos per capita com a renda per capita ou com o 
IDH-M. Em relação aos saldos totais, os 26 municípios com saldo total acima de R 50 milhões são normalmente municípios populosos (apenas três desses municípios têm uma população inferior a 40 mil habitantes) e cinco desses municípios estão também entre aqueles de maior saldo per capita.

\section{Fundo Constitucional de Financiamento do Centro- Oeste (FCO)}

O Fundo Constitucional de Financiamento do Centro-Oeste (FCO) visa contribuir para o desenvolvimento econômico e social da Região Centro-Oeste, mediante a execução de programas de financiamento às atividades produtivas dos setores agropecuário, industrial, agroindustrial, mineral, infra-estrutura, de turismo, comércio e serviços. Esse fundo é operacionalizado pelo Banco do Brasil (BB), tendo como área de atuação os Estados da Região Centro-Oeste (Mato Grosso, Mato Grosso do Sul e Goiás) mais o Distrito Federal, abrangendo 463 municípios.

O FCO tem disponibilidade de recursos semelhante ao FNO, já que esses dois fundos recebem cada um o equivalente a $0,6 \%$ da arrecadação conjunta do Imposto de Renda (IR) e do Imposto sobre Produtos Industrializados (IPI). Da mesma forma que os demais fundos constitucionais de financiamento, mas, em proporção menor, o FCO não empresta todos os recursos anuais disponíveis para empréstimo. Em 2004, por exemplo, o FCO tinha uma disponibilidade de recursos da ordem de R $\$ 1,58$ bilhão de reais, tendo emprestado $\mathrm{R} \$ 1,17$ bilhão; equivalente a $74 \%$ dos recursos efetivamente disponíveis para serem emprestados.

Da forma idêntica ao que foi feito nas seções anteriores, analisa-se o saldo dos empréstimos do FCO utilizando vários critérios e cruzando os dados de empréstimos com dados municipais censitários. O objetivo desse cruzamento de dados é investigar se os recursos do FCO se direcionam, prioritariamente, para aqueles municípios menos desenvolvidos. 
GRÁFICO 3- REPASSES ANUAIS DO TESOURO NACIONAL E APLICAÇÕES DO FCO (1994 -2004)

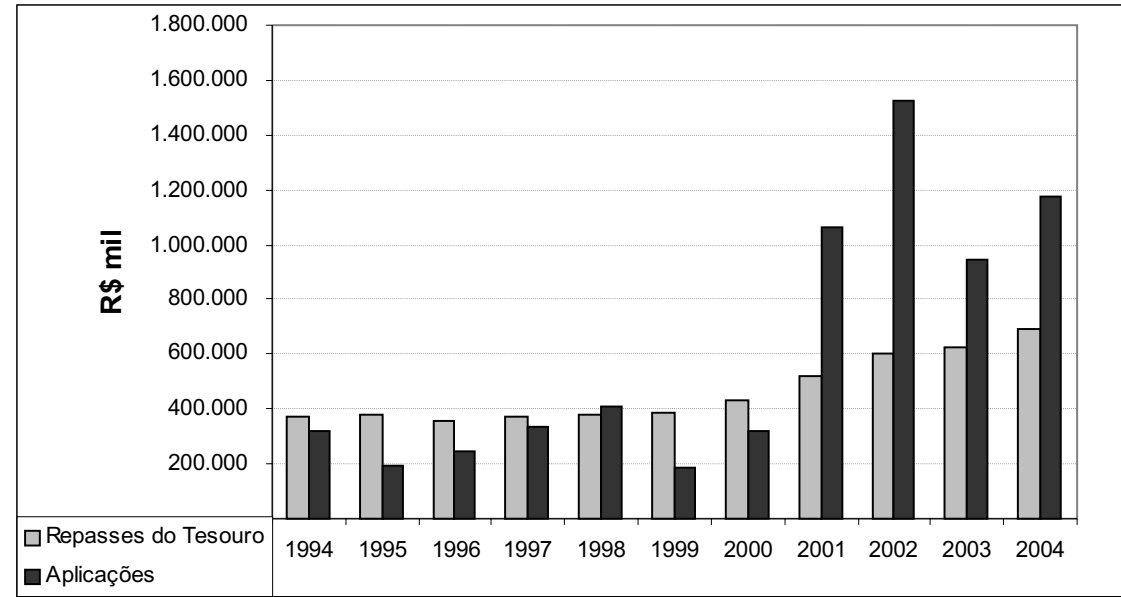

FONTE: Min. da Integração Nacional. OBS: valores atualizados para 2004 pela TR.

\subsection{Distribuição espacial dos recursos do FCO}

A Tabela 6 mostra alguns indicadores básicos do FCO para os Estados da Região Centro-Oeste e Distrito Federal. De imediato, é possível observar que o maior percentual (38\%) dos recursos liberados pelo FCO até dezembro de 2004 foi para o Estado de Goiás. Esse dado já era até certo ponto esperado, já que Goiás concentra $43 \%$ da população residente da Região Centro-Oeste. Quando se analisa o saldo dos empréstimos per capita, pode-se constatar que é o Estado de Mato Grosso aquele que mais recebe recursos, com um saldo per capita cerca de quatro vezes maior do que o saldo per capita do Distrito Federal.

TABELA 6- SALDO FCO E SALDO FCO PER CAPITA DOS ESTADOS DA REGIÃO CENTRO-OESTE E DISTRITO FEDERAL

\begin{tabular}{lccc}
\hline \multicolumn{1}{c}{ Estado } & $\begin{array}{c}\text { População } \\
\mathbf{2 0 0 0}\end{array}$ & $\begin{array}{c}\text { Saldo FCO - } \\
\text { R\$ de 2004 }\end{array}$ & $\begin{array}{c}\text { Saldo FCO Per } \\
\text { Capita (2004) }\end{array}$ \\
\hline Distrito Federal & 2.051 .146 & 349.478 .000 & 170,38 \\
Goiás & 5.003 .228 & 2.037 .108 .000 & 407,16 \\
Mato Grosso do Sul & 2.078 .001 & 1.257 .614 .000 & 605,20 \\
Mato Grosso & 2.504 .353 & 1.755 .059 .000 & 700,80 \\
\hline Total & $\mathbf{1 1 . 6 3 6 . 7 2 8}$ & $\mathbf{5 . 3 9 9 . 2 5 9 . 0 0 0}$ & $\mathbf{4 6 3 , 9 8}$ \\
\hline
\end{tabular}

FONTE: Min da Integração Nacional, Censo 2000 e IBGE 
Da mesma forma ao realizado nas seções anteriores, tenta-se identificar relações entre as liberações de recursos por município com indicadores econômicos e sociais. A idéia é investigar se os municípios mais pobres da região Centro-Oeste conseguem mais créditos do FCO do que os municípios mais ricos. Como a região Centro-Oeste é uma das regiões do Brasil que mais cresceu ao longo dos anos 90, comparam-se os dados de empréstimo do FCO de dezembro de 2004 com dados do Censo de 1991, quando os fundos constitucionais estavam na sua fase inicial, pois os critérios de alocação de recursos com a finalidade de promover o desenvolvimento regional e intra-regional deveriam seguir os indicadores do inicio da década anterior.

Os dois mapas a seguir (7 e 8) identificam os municípios na área de atuação do FCO com menor IDH-M em 1991 (inferior 0,627) e os municípios com maior saldo do FCO per capita em 2004 (superior a $\left.\mathrm{R} \$ 1_{1.266}\right)^{10}$, totalizando 134 municípios de um total de 463 municípios na área de atuação do FCO.

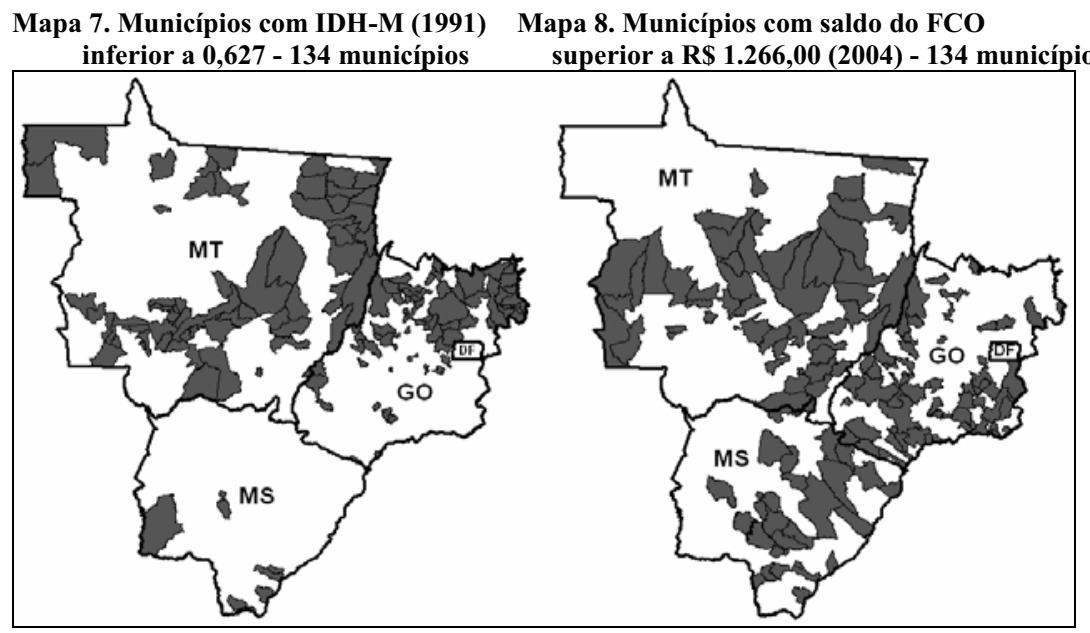

FONTE: Min. da Integração Nacional e Atlas do Desenvolvimento Humano.

10 O critério para estabelecer o valor de corte foi a média do IDH-M para o grupo de municípios da região Centro-Oeste: o,627. Como existem 134 municípios abaixo desta média, calcula-se o valor do saldo per capita do FCO no qual se tem um grupo equivalente de 134 municípios acima desse valor. 
Caso os empréstimos do FCO fossem prioritariamente dirigidos para aquelas áreas de menor IDH-M, esses dois mapas deveriam ser iguais, ou seja, a área marcada do Mapa 7 deveria ser idêntica àquela marcada do Mapa 8. Todavia, não é isso que ocorre ${ }^{11}$.

Nos mapas acima, é possível observar que as áreas com maior saldo de empréstimo do FCO não coincidem com aquelas áreas de menor IDH-M. Essa diferença fica mais clara para o Estado de Goiás, que tem sua área mais pobre no Nordeste do Estado, enquanto os municípios com maior saldo de empréstimos per capita agrupam-se na região Sul e Oeste do Estado. Na verdade, dos 134 municípios na área de atuação do FCO com IDH-M inferior a 0,627 , apenas 29 desses municípios (22\%) estão também entre aqueles que receberam mais de $\mathrm{R} \$ 1.266$ per capita de empréstimo do FCO até dezembro de 2004. Isso significa que a maior parte dos empréstimos do FCO não foi alocada para aqueles municípios que tinham menor IDH-M em 2000, o que sugere que as liberações de recursos desse fundo, assim como os demais, respondem à demanda por financiamento naqueles municípios onde já há dinamismo econômico.

\subsection{Saldo de empréstimos do FCO: municípios que mais receberam recursos}

A Tabela 7 mostra, por faixa de IDH-M, o número de municípios na área de atuação do FCO e o número de municípios cujo saldo per capita em dezembro de 2004 era superior a $\mathrm{R} \$ \mathbf{1 . 5 0 0 , 0 0}$. Cerca de $22 \%$ dos municípios da área de atuação do FCO tinham saldo per capita superior a esse valor no final de 2004 e desses municípios o maior número absoluto e relativo está naqueles municípios de IDH-M alto (acima de o,688). Comparando com o FNE e FNO, um maior número absoluto e relativo de municípios na Região Centro-Oeste tem saldo per capita superior a $\mathrm{R} \$ 1.500$. Isso sugere, como nos outros fundos, que os empréstimos do FCO parecem responder mais à demanda do que ao objetivo de redução da desigualdade intra-regional.

11 Dado que não existe uma relação clara entre IDH-M e saldo dos empréstimos do FCO per capita, é possível tentar identificar se existe alguma relação entre PIB per capita dos municípios e o saldo dos empréstimos per capita do FCO. Isso foi feito e novamente não se encontra qualquer relação clara entre essas duas variáveis, o que indica que as liberações do FCO não se direcionam prioritariamente para os municípios mais pobres. 
TABELA 7- NÚMERO DE MUNICÍPIOS COM SALDO PER CAPITA DE EMPRÉSTIMO DO FCO ACIMA DE R\$ 1.500,00 POR FAIXA DE IDH

\begin{tabular}{ccrr} 
IDH & $\begin{array}{c}\text { Municípios com Saldo } \\
\text { FCO Per Capita }>\text { R } \$ \\
1.500 \text { (a) }\end{array}$ & $\begin{array}{c}\text { Municípios na área de } \\
\text { atuação do FCO (b) }\end{array}$ & (a) / (b) - \% \\
\hline $\mathbf{0 , 5 0 - 0 , 6 2 7}$ & 18 & 134 & $13 \%$ \\
$\mathbf{0 , 6 2 7 - 0 , 6 8 8}$ & 52 & 240 & $22 \%$ \\
$\mathbf{0 , 6 8 8 - 0 , 8 0}$ & 31 & 89 & $35 \%$ \\
\hline Totais & $\mathbf{1 0 1}$ & $\mathbf{4 6 3}$ & $22 \%$ \\
\hline
\end{tabular}

FONTE: Min. da Integração e Ipeadata

Quando se cruzam os dados de empréstimo do FCO per capita com dados de renda IDH-M para o grupo de 101 municípios com saldo per capita acima de R\$ 1.500 não é possível encontrar qualquer relação. Em relação à comparação do saldo total com o saldo per capita, da mesma que nos outros dois fundos, os municípios com maior saldo per capita são municípios pouco populosos. Apenas 10 dos 101 municípios com saldo per capita acima de $\mathrm{R} \$ 1.500$ têm mais de 20.000 habitantes. No total, a população dos municípios com saldo per capita dos empréstimos do FCO superior a $\mathrm{R} \$ 1.500$ é de 1,2 milhão de habitantes, enquanto a população dos demais municípios na área de atuação do FCO é de 10,4 milhões de habitantes.

Em relação aos municípios que tinham saldo total superior a $\mathrm{R} \$ 50$ milhões em 2004, esses são na sua maioria municípios populosos, totalizando 6 milhões de habitantes em um grupo de apenas 31 municípios, incluindo as capitais dos Estados e Brasília. Esses 6 municípios responderam por $\mathrm{R} \$ 3,8$ bilhões (46\%) do total de $\mathrm{R} \$ 8,3$ bilhões emprestados até dezembro de 2004 pelo FCO e são municípios com IDH-M elevado (acima de 0,75 pelo IDH-M 2000). Esse é exatamente o mesmo padrão encontrado para os municípios que mais recebem recursos do FNO.

Da mesma forma que nos demais fundos, parte dos municípios com maior saldo per capita estão também entre aqueles com saldo total superior a $\mathrm{R} \$ 50$ milhões. No caso do FCO, essa intersecção é maior, já que envolve $50 \%$ dos municípios com saldo total superior a R\$ 50 milhões (16 dos 31 municípios). Esse índice é o maior entre os três fundos, o que reforça a percepção de que o FCO, mais do que o FNE e FNO, responde fortemente à demanda daqueles municípios mais desenvolvidos.

Em resumo, no FCO, assim como no FNE e no FNO, baseando-se apenas em estatísticas descritivas, não é possível estabelecer uma relação clara entre os saldos dos empréstimos per capita com a renda per capita ou com o IDH-M. Em relação aos saldos totais, os 31 municípios com saldo total acima de $\mathrm{R} \$ 50$ milhões são normalmente municípios populosos e 16 desses municípios estão também entre aqueles de maior saldo per capita. 


\section{Análise exploratória de dados espacias}

Nas seções anteriores, por meio de cartogramas, mostra-se que não há correlação entre municípios de baixo desenvolvimento socioeconômico (medido pelo IDH-M) e seus saldos per capita de empréstimos dos fundos constitucionais de financiamento. Contudo, nessa análise puramente visual, pode haver dúvidas a respeito dessa ausência de direcionamento dos recursos desses fundos constitucionais para os municípios mais pobres. Assim, nesta seção, apresenta-se uma métrica que permita avaliar de maneira mais analítica a existência ou não de correlação espacial entre o IDH-M e os recursos do FNE, FNO e FCO.

Nesse sentido, utiliza-se o teste I de Moran no intuito de construir uma análise exploratória dos dados espaciais, analisando se existe autocorrelação espacial nos índices do IDH-M e se existe autocorrelação espacial entre os índices IDH-M e o saldo per capita dos municípios vizinhos.

A estatística ou índice $I$ de Moran é uma estatística de autocorrelação espacial que indica se a distribuição dos dados no espaço segue algum padrão não aleatório. Caso exista um padrão espacial para a variável em análise, IDH-M (IDH-M e o saldo per capita dos municípios vizinhos), há duas possibilidades: autocorrelação positiva, caso em que os valores semelhantes se aproximam no espaço; ou, negativa, caso em que os valores se distanciam espacialmente.

A análise visual do Gráfico 5 sugere a existência de autocorrelação espacial positiva nos índices de IDH-M dos municípios contemplados com recursos do fundos constitucionais de financiamento, visto que os pontos se concentram nos primeiro e terceiro quadrantes. Verifica-se, pois, que municípios com alto (baixo) índice de IDH- $\mathrm{M}^{12}$, em média, são vizinhos de municípios com alto (baixo) índice de IDH-M ${ }^{13}$.

12 Mencione-se que alto (baixo) índice, aqui, refere-se ao índice acima (abaixo) da média padronizada dos IDH-M presentes na estimativa.

13 Corroborando a análise visual, a estatística de I de Moran mostrou-se significante em um nível de $0,01 \%$, a partir de testes com aproximadamente 10.000 permutações. 


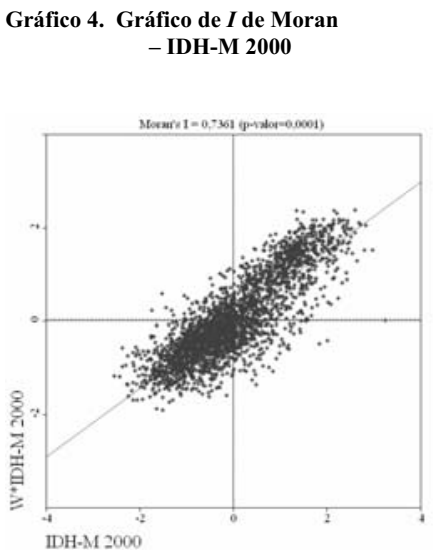

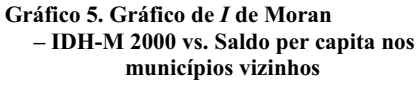

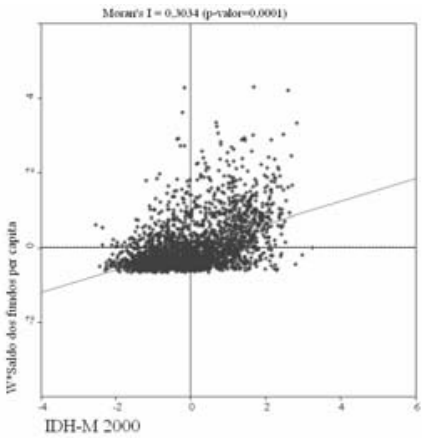

FONTE: elaboração dos autores com dados do Min. da Integração Nacional e Atlas do Desenvolvimento Humano.

Por sua vez, no Gráfico 6, percebe-se a existência de autocorrelação espacial positiva nos índices de IDH-M e o saldo per capita de recursos dos fundos constitucionais de financiamento dos municípios vizinhos ${ }^{13}$. Ora, desde que pelo Gráfico 5 ricos (pobres) são vizinhos de ricos (pobres), então o Gráfico 6 sugere que os municípios ricos (pobres) são vizinhos de municípios com alto (baixo) saldo per capita de recursos desses fundos e, conseqüentemente, afirma-se que essa análise exploratória de dados ratifica a ausência de direcionamento dos recursos dos fundos constitucionais de financiamento para os municípios mais pobres.

\section{Conclusões}

Ao longo deste artigo, analisa-se o comportamento dos três fundos constitucionais de financiamento (FNE, FNO e FCO) com a finalidade de destacar alguns fatos estilizados. Entre as principias conclusões, destacam-se as seguintes:

a) Excesso de oferta: nos últimos anos, predomina uma situação de excesso de oferta nos fundos constitucionais de financiamento, apesar de em 2004 os bancos (BNB, Basa e Banco do Brasil) terem sido mais eficientes na liberação de recursos. Nesse ano, o banco com o maior volume de recursos disponíveis e não aplicado é o BNB;

b) Empréstimos por município: mais da metade (2.864) dos municípios do Brasil estão na área de atuação de um dos três fundos constitucionais de financiamento, sendo 1.952 na área do FNE, 449 na área do FNO e 463 na área do FCO. Identifica-se que os recursos dos fundos constituci- 
onais de financiamento não se direcionam prioritariamente para os municípios de menor IDH-M ou de menor renda per capita. Isso indica que os empréstimos dos fundos constitucionais de financiamento respondem à demanda daqueles municípios que já possuem algum dinamismo econômico;

c) Municípios de menor IDH-M e saldo per capita: quando se cruzam os municípios de maior saldo per capita com aqueles de menor IDH$\mathrm{M}$, apenas 34\% dos municípios na área de atuação do FNO e FNE obedecem a esse critério e, no caso do FCO, apenas $22 \%$ dos municípios de menor IDH-M estão também entre aqueles de maior saldo per capita. Dado que o objetivo constitucional desses fundos é reduzir as desigualdades regionais, esse objetivo pode estar sendo paradoxalmente alcançado pelo direcionamento dos empréstimos para aquelas áreas mais dinâmicas das Regiões Nordeste, Norte e Centro-Oeste, o que pode estar contribuindo para redução das desigualdades inter-regionais, à custa do aumento da desigualdade intra-regional em cada uma dessas regiões;

d) Empréstimos per capita por município: do total de municípios com saldo de empréstimos per capita superior a $\mathrm{R} \$ 1.500,00 ; 58$ deles estão na área de atuação do FNE, 67 da área de atuação do FNO e 101 municípios na área de atuação do FCO. Isso indica que um número relativamente maior de municípios na área de atuação do FCO tem empréstimos mais elevados do que nas Regiões Norte e Nordeste.

A conclusão mais robusta deste estudo é que os empréstimos dos fundos constitucionais de financiamento não se direcionam de forma prioritária para os municípios mais pobres. Isso indica que os empréstimos dos fundos constitucionais de financiamento parecem responder fortemente à demanda de empresas em municípios que já contam com algum dinamismo econômico, o que implicaria um aumento da desigualdade intra-regional com possíveis impactos positivos para a redução das desigualdades inter-regionais, pois os empréstimos estariam sendo direcionados, sobretudo, para áreas de maior dinamismo econômico nas Regiões Norte, Nordeste e Centro-Oeste.

Por fim, cabe destacar que não é objetivo explícito dos fundos constitucionais de financiamento priorizar a liberação de recursos para as áreas menos desenvolvidas das três regiões que formam sua área de atuação. Apenas recentemente isso parece ser uma preocupação na programação das aplicações dos fundos constitucionais de financiamento, com a gestão do Ministério da Integração no primeiro mandato do governo Lula, a qual incorpora a idéia de que o combate às desigualdades regionais implica, também, o combate às desigualdades intra-regionais. No entanto, ainda é cedo para tecer conclusões sobre esse novo objetivo, que apenas 
recentemente foi incorporado à política de aplicação dos fundos constitucionais de financiamento.

\section{Referências}

ARAÚJO, T. B. (1995). “Nordeste, nordestes: que nordeste?” In AFFONSO, R. \& SILVA, P. (orgs.). Desigualdades regionais e desenvolvimento. São Paulo: Fundap, Editora da Unesp.

BRASIL (vários anos a). Ministério da Integração Nacional. Programação de Financiamento para o Fundo Constitucional de Financiamento do Nordeste.

BRASIL (vários anos b). Programação de Financiamento para o Fundo Constitucional de Financiamento do Norte.

BRASIL (vários anos c). Programação de Financiamento para o Fundo Constitucional de Financiamento do Centro-Oeste.

GRUPO DE TRABALHO PARA O DESENVOLVIMENTO DO NORDESTE - GTDN (1997). "Uma política de desenvolvimento econômico para o Nordeste, 1959." Revista Econômica do Nordeste 28(4).

IBGE (1991). Censo Demográfico, 1991. Rio de Janeiro: IBGE.

IBGE (2000). Censo Demográfico, 20oo. Rio de Janeiro: IBGE.

IPEADATA (2006). Dados regionais. Disponível em: <http:// www.ipeadata.com.br>. Acesso em: 25 jan. 2006.

SANTANA, A. (coord.) (2002). O fundo constitucional de financiamento do Norte e o desenvolvimento da Amazônia. Belém-Pará: M\&S Editora.

SISTEMA DE INFORMAÇÕES GERENCIAIS DOS FUNDOS CONSTITUCIONAIS DE FINANCIAMENTO (FNE, FNO, FCO). Vários anos.

WOOLDRIDGE, J. M. (2002). Econometric analysis of cross section and panel data. Cambridge: MIT Press.

Recebido em: 15 nov. 2006

Aceite em: 4 jan. 2007 